\title{
The potential impact of policies to reduce Social Security funding shortfalls on consumers' expected benefits and behaviour - CORRIGENDUM
}

\author{
F. Perez-Arce, L. Rabinovich and J. Yoong
}

(First published online 11 December 2019)

https://doi.org/10.1017/S1474747219000234, Published by Cambridge University Press, 13th November 2019

Key words: Internet panel; policy uncertainty; shortfalls; Social Security; subjective expectations; H55; D90; C93; corrigendum

This article (Perez-Arce et al., 2019) was originally published without the following funding statement.

Research reported in this publication was supported by the National Institute on Aging of the National Institutes of Health and by the Social Security Administration, under Award No. 3R01AG020717. The content is solely the responsibility of the authors and does not necessarily represent the official views of the National Institutes of Health or the Social Security Administration. We would like to thank David Rogofsky, Laith Alattar, Richard Chard, and Barbara Smith for their invaluable input. We also thank Arie Kapteyn, Tania Gutsche, and participants at the Workshop for the Special Issue of the JPEF on "New Longitudinal Data for Retirement Analysis and Policy" for their valuable comments. Programming the Internet survey was Bart Orriens; this research project would not have been possible without him.

The article has now been updated and this corrigendum published.

\section{Reference}

Perez-Arce F, Rabinovich L, Yoong J (2019). The potential impact of policies to reduce Social Security funding shortfalls on consumers' expected benefits and behavior. Journal of Pension Economics and Finance 1-13. https://doi.org/10.1017/ S1474747219000234

Cite this article: Perez-Arce F, Rabinovich L, Yoong J (2020). The potential impact of policies to reduce Social Security funding shortfalls on consumers' expected benefits and behaviour - CORRIGENDUM. Journal of Pension Economics and Finance 19, 568-568. https://doi.org/10.1017/S1474747219000337 